\title{
Association of CACNA1C Variants with Bipolar Disorder in the Korean Population
}

\author{
Soojin Kim¹, Chul-Hyun $\mathrm{Cho}^{2}$, Dongho Geum¹, and Heon-Jeong Lee ${ }^{1,2 凶}$ \\ ${ }^{1}$ Department of Biomedical Sciences, Korea University Medical School, Seoul, Republic of Korea \\ ${ }^{2}$ Department of Psychiatry, Korea University College of Medicine, Seoul, Republic of Korea
}

Objective Previous studies have suggested an association between CACNA1C and susceptibility of bipolar disorder. In this study, we examined the association of $C A C N A 1 C$ variants with bipolar disorder in the Korean population.

Methods We selected 2 CACNA1C single nucleotide polymorphisms (SNPs), namely, rs723672 and rs1051375, based on their functions and minor allele frequencies described in previous studies. Genotypes of these 2 SNPs were analyzed by extracting DNA from blood samples collected from 287 patients with bipolar disorder and 340 healthy controls.

Results Genotype frequencies of both rs723672 and rs1051375 SNPs were significantly different in patients and controls ( $\mathrm{p}=0.0462$ and 1.732E-14, respectively). Dominant, recessive, and allele models showed significant differences between patients and controls with respect to the rs1051375 SNP ( $\mathrm{p}=1.72 \mathrm{E}-11,4.17 \mathrm{E}-10,4.95 \mathrm{E}-16$, respectively).

Conclusion Our results suggested that CACNA1C SNPs rs723672 and rs1051375 were associated with bipolar disorder in the Korean population. In addition, our results highlighted the importance of $C A C N A 1 C$ in determining susceptibility to bipolar disorder.

Psychiatry Investig 2016;13(4):453-457

Key Words Bipolar disorder, CACNA1C, Polymorphism.

\section{INTRODUCTION}

Bipolar disorder is a psychiatric disorder characterized by the repetition of extremely elevated mood, followed by mania and depression. ${ }^{1,2}$ In the manic state, patients exhibit symptoms such as hyperactivity, talkativeness, creativity, excessive self-esteem, and decreased sleep. Some patients also experience delusions or hallucinations. ${ }^{3}$ In the depressive state, patients experience hopelessness, anxiety, lethargy, sadness, and suicidal impulse4. Although the etiology of bipolar disorder is still unclear, twin and family studies have suggested that it is a complex genetic disorder, ${ }^{5-7}$ indicating that genetic factors are an important cause of bipolar disorder. Moreover, genomewide association studies (GWAS) have indicated an association between bipolar disorder and single nucleotide polymor-

Received: November 30, 2015 Revised: February 2, 2016 Accepted: February 5, 2016 Available online: March 23, 2016

$\triangle$ Correspondence: Heon-Jeong Lee, $\mathrm{MD}, \mathrm{PhD}$

Department of Psychiatry, Korea University Hospital, Korea University College of Medicine, 73 Inchon-ro, Seongbuk-gu, Seoul 02841, Republic of Korea Tel: +82-2-920-6721, Fax: +82-2-929-7679, E-mail: leehjeong@korea.ac.kr

(a) This is an Open Access article distributed under the terms of the Creative Commons Attribution Non-Commercial License (http://creativecommons.org/licenses/bync/3.0) which permits unrestricted non-commercial use, distribution, and reproduction in any medium, provided the original work is properly cited. phisms (SNPs) in DGKH, BCR, TPH2, BDNF, ANK3, and CACNA1C. ${ }^{8-12}$

CACNA1C, which encodes the alpha-1 subunit of voltagegated calcium channel CaV1.2, plays an important role in calcium ion influx into cells. Because calcium channels are essential components of various calcium-dependent processes such as gene expression regulation, programmed cell death, neurotransmitter release, and muscle contraction, studies have focused on CACNA1C as a candidate gene associated with various diseases, especially psychiatric diseases. ${ }^{13}$ Furthermore, increasing number of studies are being performed on $C A C$ $N A 1 C$ because the alpha 1 subunit of L-type calcium channel is a target of all well-known calcium channel blockers such as benzothiazepines. ${ }^{14}$ Various GWAS, meta-analyses, and replication studies have repeatedly highlighted the association between CACNA1C SNPs and bipolar disorder. ${ }^{12,15-18}$ For example, rs1006737, one of the most frequently studied $C A C$ NA1C SNP, is associated with affective personality traits, intracellular calcium homeostasis, and amygdala activity. ${ }^{19-21}$

In the present study, we determined the association between CACNA1C SNPs rs723672 and rs1051375 and bipolar disorder in the Korean population to understand genetic causes underlying bipolar disorder. 


\section{METHODS}

\section{Study population}

\section{Patients with bipolar disorder}

All patients who met DSM-IV-TR criteria for bipolar disorder type 1 or 2 were recruited from Korea University Hospital, Seoul, between March 2009 and August 2015. All the patients were ethnically homogeneous Koreans and were examined by trained psychiatrists by using the Korean version of Structured Clinical Interview for DSM-IV, leading to a diagnosis based on DSM-IV criteria. ${ }^{22}$ Written informed consent was obtained from each patient, and study protocols were approved by the Ethics Committee of the Korea University Hospital. None of the patients included in the study had significant comorbid neurological illnesses, mental retardation, or history of substance abuse.

\section{Healthy controls}

In all, 340 community-based healthy adults were recruited through a newspaper advertisement. The age of healthy controls ranged from 23 to 83 years. Absence of lifetime or current psychiatric disorders in healthy controls was confirmed by an experienced psychiatrist by using Mini-International Neuropsychiatric Interview. Subjects with a family history of substance abuse or major psychiatric disorders (e.g., schizophrenia or mood disorders) were excluded. All the healthy controls were unrelated Koreans who did not have any major medical problems and who lived in Seoul, Korea. Informed consent was obtained from all the healthy controls.

\section{Genotyping}

Blood samples $(5-10 \mathrm{~mL})$ from all the study subjects were collected in EDTA-coated tubes, and genomic DNA was extracted from leukocytes by using QIAamp Blood Kit (Qiagen, Germany). Genotyping was performed using high-resolution melting (HRM) curve analysis. PCR was performed using 96-well CFX96 Real-Time PCR System (Bio-Rad, Hercules, $\mathrm{CA}$ ) in a $20-\mu \mathrm{L}$ reaction mixture containing $1.5 \mu \mathrm{L}$ genomic DNA as the template, $200 \mathrm{mM}$ of each primer (CACNA1C rs723672: forward 5'-CACTTCTACAACCGCTCT-3' and reverse 5'-TCCAAGGAGGAGGAATACA-3'; CACNA1C rs 1051375: forward 5'-CAACGCCAACATCAACAAC-3' and reverse 5'-GTCTCCTCCACTGTCTCC-3'), $1 \times$ SsoFast EvaGreen Supermix (Bio-Rad), and sterile H2O. Amplification protocol was as follows: initial denaturation at $98^{\circ} \mathrm{C}$ for $3 \mathrm{~min}$, followed by 39 cycles of denaturation at $98^{\circ} \mathrm{C}$ for $10 \mathrm{~s}$ and annealing at $58^{\circ} \mathrm{C}$ for $20 \mathrm{~s}$. After an initial cycle of denaturation at $95^{\circ} \mathrm{C}$ for $10 \mathrm{~s}$ and annealing at $65^{\circ} \mathrm{C}$ for $10 \mathrm{~s}$, melting curves were generated from $65^{\circ} \mathrm{C}$ to $95^{\circ} \mathrm{C}$, with increments of $0.3^{\circ} \mathrm{C} /$ cycle. Melting profiles were analyzed using Precision Melt Analysis Software (Bio-Rad).

\section{DNA sequencing}

Some PCR products were randomly selected for DNA sequencing. Amplicons containing SNPs were generated by performing PCR with AC1000 thermal cycler (Bio-Rad) in a $20-\mu \mathrm{L}$ reaction mixture containing $1.0 \mu \mathrm{L}$ genomic DNA as the template, $0.5 \mu \mathrm{M}$ of each primer (CACNA1C rs723672: forward 5'-CGTGGAACTTGCTGTGGTTG-3' and reverse 5'-CGCTGAACGCTTCCAGATGT-3'; CACNA 1C rs 1051375: forward 5'-ACCCCTCCTTCTTGCCTACA-3' and reverse 5'-CTGCCAGGTCTGATCAAGGG-3'), AccuPower ${ }^{\circledR}$ PCR Premix (Bioneer, Daejeon, Korea), and sterile $\mathrm{H}_{2} \mathrm{O}$. Amplification protocol was as follows: initial denaturation at $93^{\circ} \mathrm{C}$ for $3 \mathrm{~min}$, followed by 35 cycles of denaturation at $94^{\circ} \mathrm{C}$ for $20 \mathrm{~s}$, annealing at $55^{\circ} \mathrm{C}$ for $30 \mathrm{~s}$, and elongation at $72^{\circ} \mathrm{C}$ for $30 \mathrm{~s}$. PCR products were confirmed by performing electrophoresis on a $1.5 \%$ agarose gel (USB Corporation, $\mathrm{Cl}$ eveland, OH, USA) and were sequenced using ABI 3730XL capillary sequencer (Applied Biosystems, Carlsbad, CA, USA) and BigDye ${ }^{\circledR}$ Terminator v3.1 Cycle Sequencing Kit.

\section{Statistical analysis}

Conformance with Hardy-Weinberg equilibrium was determined using chi-square $\left(\chi^{2}\right)$ test for goodness of fit. Probability value of $<0.05$ was considered statistically significant. Power calculation was performed using G*Power 3.1.9 (Dusseldorf, Germany). ${ }^{23}$ In all, 429 samples ( $\mathrm{df}=2$ ) were required to detect an SNP of the effective size and power (80\%). Statistical analyses were performed using SPSS 18.0 for Windows (SPSS Inc., Chicago, IL, USA) and SNPAlyze version 7 (Dynacom, Chiba, Japan).

\section{RESULTS}

\section{Demographic data}

Demographic information of patients with bipolar disorder and healthy controls is presented in Table 1. The study included 627 subjects, of which 287 were patients and 340 were healthy controls. Of the 287 patients, 131 were men and 169 were women, with an average age of 37.02 years. The mean age of disease onset among the patients was 24.24 years, and the average number of total episodes was 9.18. Of the 340 healthy controls, 155 were men and 171 were women, with an average age of 33.55 years (Table 1 ).

\section{Genotype distribution and allele frequencies of rs723672 and rs1051375}

Genotype distribution of rs723672 and rs1051375 is shown 
in Table 2. Genotype distribution of both rs723672 and rs1051375 followed the Hardy-Weinberg equilibrium. In patients with bipolar disorder, frequencies of rs723672 genotypes $\mathrm{T} / \mathrm{T}, \mathrm{T} / \mathrm{C}$, and $\mathrm{C} / \mathrm{C}$ were $64.5 \%, 30.7 \%$, and $4.9 \%$, respectively, and frequencies of $\mathrm{T}$ and $\mathrm{C}$ alleles were $79.8 \%$ and $20.2 \%$, respectively. In healthy controls, frequencies of rs 723672 genotypes $\mathrm{T} / \mathrm{T}, \mathrm{T} / \mathrm{C}$, and $\mathrm{C} / \mathrm{C}$ were $66.8 \%, 31.8 \%$, and $1.5 \%$, respectively, and frequencies of $\mathrm{T}$ and $\mathrm{C}$ alleles were $82.6 \%$ and $17.4 \%$, respectively. Further, in patients with bipolar disorder, frequencies of rs 1051375 genotypes A/A, A/G, and G/ G were $41.5 \%, 43.2 \%$, and $15.3 \%$, respectively, and frequencies of $A$ and $G$ alleles were $63.1 \%$ and $36.9 \%$, respectively. In healthy controls, frequencies of rs1051375 genotypes A/A, $\mathrm{A} / \mathrm{G}$, and $\mathrm{G} / \mathrm{G}$ were $68.2 \%, 30.0 \%$, and $1.8 \%$ and frequencies of $A$ and $G$ alleles were $83.2 \%$ and $16.8 \%$, respectively.

Results of HRM analysis were validated by randomly selecting blood samples for direct sequencing. Results of direct sequencing were parallel to those of HRM analysis.

Genotype model showed statistically significant differences between patients with bipolar disorder and healthy controls

Table 1. Demographic characteristics of study population

\begin{tabular}{lcc}
\hline \multicolumn{1}{c}{ Characteristics } & $\begin{array}{c}\text { BP patients } \\
\mathrm{N}=287\end{array}$ & $\begin{array}{c}\text { Controls } \\
\mathrm{N}=340\end{array}$ \\
\hline Gender $(\mathrm{M} / \mathrm{F})$ & $131 / 169$ & $155 / 171$ \\
Age (years $\pm \mathrm{SD})$ & $37.02 \pm 15.28$ & $33.55 \pm 10.87$ \\
Bipolar type $(\mathrm{I} / \mathrm{II})$ & $218 / 79$ & $\mathrm{~N} / \mathrm{A}$ \\
Education (years $\pm \mathrm{SD})$ & $13.48 \pm 2.99$ & $14.37 \pm 2.77$ \\
Age of onset $($ years $\pm \mathrm{SD})$ & $24.24 \pm 9.65$ & $\mathrm{~N} / \mathrm{A}$ \\
Total Episodes $(\mathrm{n} \pm \mathrm{SD})$ & $9.18 \pm 12.17$ & $\mathrm{~N} / \mathrm{A}$ \\
\hline
\end{tabular}

SD: standard deviation with respect to the rs723672 and $\mathrm{rs} 1051375$ SNPs ( $\mathrm{p}_{\mathrm{Geno}}=$ 0.0462 and $\mathrm{p}_{\mathrm{Geno}}=1.732 \mathrm{E}-14$, respectively). In addition, both recessive and dominant allele models showed statistically significant differences between patients with bipolar disorder and controls with respect to the rs 1051375 SNP, indicating that the frequency of the A/G heterotype of the rs1051375 SNP was higher in patients with bipolar disorder than in controls $\left(p_{\text {Rec }}=4.172 \mathrm{E}-10\right.$ and $p_{\text {Dom }}=1.72 \mathrm{E}-11$, respectively). More patients with bipolar disorder harbored the $\mathrm{C}$ allele of the rs723672 SNP than controls ( $\mathrm{p}_{\mathrm{Rec}}=0.0131$ ) (Table 3).

\section{DISCUSSION}

As an L-type voltage-gated $\mathrm{Ca}^{2+}$ channel, CACNA1C contributes to the depolarization of neurons through calcium ion influx. ${ }^{24}$ Variations in SNPs in CACNA1C affect both the structure and function of the nervous system, ${ }^{25}$ including synaptic plasticity and neuron viability. ${ }^{13}$ Association of CACNA1C SNPs with Timothy syndrome, fear conditioning, major depression, and schizophrenia 26-29 has been found, and correlation with bipolar disorder was also reported through GWAS study. ${ }^{12}$ The association between bipolar disorder and CACNA1C SNPs has been examined in Han Chinese population (HCP).$^{30}$ However, only the association between schizophrenia and CACNA1C SNPs has been examined in the Korean population. ${ }^{31}$ Therefore, our study is the first to directly analyze the association between CACNA1C SNPs and bipolar disorder.

Although the genotype frequencies of rs1051375 in our control group showed statistically different frequencies compared to those observed in Han Chinese population (HCP) in the

Table 2. Genotype and allele frequencies of study population

\begin{tabular}{|c|c|c|c|c|c|c|}
\hline \multirow[b]{2}{*}{ rs723672 } & \multicolumn{3}{|c|}{ Genotype distribution } & \multicolumn{2}{|c|}{ Allele frequency (\%) } & \multirow[t]{2}{*}{$\mathrm{HWE}^{\mathrm{P}}$} \\
\hline & $\mathrm{T} / \mathrm{T}$ & $\mathrm{T} / \mathrm{C}$ & $\mathrm{C} / \mathrm{C}$ & $\mathrm{T}$ & $\mathrm{C}$ & \\
\hline Patients & 185 & 88 & 14 & 79.8 & 20.2 & 0.40 \\
\hline Controls & 227 & 108 & 5 & 82.6 & 17.4 & 0.05 \\
\hline rs1051375 & $\mathrm{A} / \mathrm{A}$ & $\mathrm{A} / \mathrm{G}$ & G/G & A & G & \\
\hline Patients & 119 & 124 & 44 & 63.1 & 36.9 & 0.22 \\
\hline Controls & 232 & 102 & 6 & 83.2 & 16.8 & 0.17 \\
\hline
\end{tabular}

HWE': Hardy-Weinburg equilibrium $\mathrm{p}$ value

Table 3. Genetic association of SNPs in the patients and control groups

\begin{tabular}{lcccccccc}
\hline & \multicolumn{1}{c}{ Model } \\
\cline { 2 - 10 } & \multicolumn{2}{c}{ Genotype } & \multicolumn{2}{c}{ Recessive } & \multicolumn{2}{c}{ Dominant } & \multicolumn{2}{c}{ Allele } \\
\hline$\chi^{2}$ & rs723672 & rs1051375 & rs723672 & rs1051375 & rs723672 & rs1051375 & rs723672 & rs1051375 \\
p value & 2.2869 & 63.3167 & 4.2869 & 40.5487 & -1.6334 & 43.6977 & -0.3314 & 64.163 \\
OR & $0.0462^{*}$ & $1.732 \mathrm{E}-14^{*}$ & $0.0131^{*}$ & $4.172 \mathrm{E}-10^{*}$ & 0.5447 & $1.72 \mathrm{E}-11^{*}$ & 0.1959 & $4.953 \mathrm{E}-16^{*}$ \\
\hline
\end{tabular}

${ }^{*} \mathrm{p}<0.05$. OR: odds ratio, SNP: single nucleotide polymorphism 


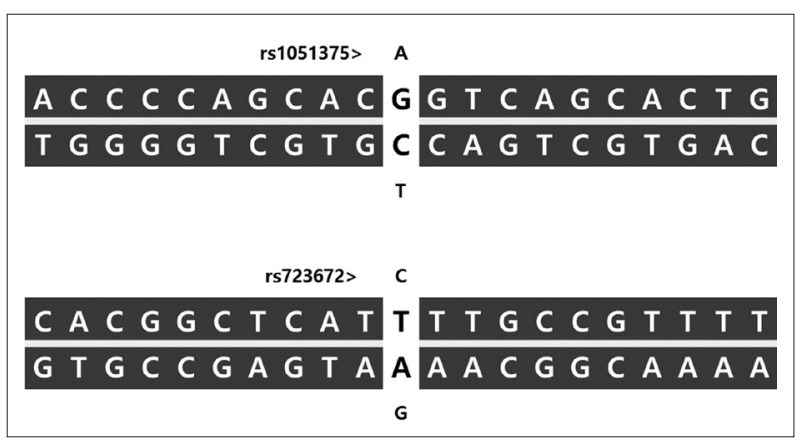

Figure 1. Single nucleotide polymorphisms in rs 1051375 and rs723672 locus.

study by Zhang et al., ${ }^{30}$ results of the present study and those of the previous study highlight the association between rs723672 SNP and bipolar disorder $\left(\mathrm{p}_{\mathrm{HCP}}=0.005\right.$ and $\mathrm{p}_{\mathrm{KOR}}=$ 1.732E-14). In addition, unlike that observed in the HCP, we observed that the rs723672 SNP was associated with bipolar disorder $\left(\mathrm{p}_{\mathrm{HCP}}=0.30\right.$ and $\mathrm{p}_{\mathrm{KOR}}=0.0462$ ).

However, further studies should be performed to determine the mechanisms underlying the effect of CACNA1C rs723672 and rs1051375 SNPs on the expression and function of the Ltype voltage-gated $\mathrm{Ca}^{2+}$ channel. Particularly, the $\mathrm{G}$ allele, which is dominant in the rs $1051375 \mathrm{SNP}$, creates a CpG site containing a cytosine nucleotide adjacent to a guanine nucleotide. Although the rs1051375 SNP does not directly affect the primary structure of the L-type voltage-gated $\mathrm{Ca}^{2+}$ channel, it may serve as a methylation site (Figure 1). Although it is unclear whether this $\mathrm{CpG}$ site undergoes methylation, a study showed that $70-80 \%$ cytosines in CpG sites of mammalian genomes are methylated. ${ }^{32}$ Therefore, it is highly likely that the rs1051375 SNP contributes to epigenetic regulation through the methylation of CACNA1C. Moreover, a study showed that DNA methylation pattern of CACNA1C is specific in neuronal cells, thus reinforcing that changes in methylation patterns of specific sites in CACNA1C can induce psychiatric disorders by modulating neuronal activity.

However, our study has some limitations. First, the average age of healthy controls was slightly lower than that of patients with bipolar disorder, suggesting that the healthy controls could develop bipolar disorder as they aged. Although this possibility bridged the difference between the 2 groups, a meaningful difference was still observed in our study. Second, genotype distribution of the rs723672 SNP slightly deviated from the Hardy-Weinberg equilibrium in healthy controls. However, this deviation was very small to refute the assumption that the rs723672 SNP is underlying the Hardy-Weinberg equilibrium. These data were verified by performing repeated HRM analyses. Third, haplotype combinations were not analyzed because $L D$ value was not significant between the rs723672 and rs1051375 SNPs ( $\left.D^{\prime}=-9.609 \mathrm{E}-3\right)$.
In conclusion, the results of our study suggested the association of CACNA1C rs723672 and rs1051375 SNPs with bipolar disorder in the Korean population, thus supporting the hypothesis that CACNA1C is involved in the pathogenesis of bipolar disorder. Our data together with those of other studies highlight an association between CACNA1C SNPs and bipolar disorder. these results will provide useful insights for performing further research to determine genetic causes underlying bipolar disorder.

\section{Acknowledgments}

This study was supported by the Korea Health 21 R\&D Project funded by the National Research Foundation of Korea (2012M3A9C7050135) and the Korean Health Technology R\&D Project, Ministry of Health \& Welfare, Republic of Korea (HI14C1731).

\section{REFERENCES}

1. Anderson IM, Haddad PM, Scott J. Bipolar disorder. BMJ 2012;345: e8508.

2. Jann MW. Diagnosis and treatment of bipolar disorders in adults: a review of the evidence on pharmacologic treatments. Am Health Drug Benefits 2014;7:489-499.

3. Berrios GE. Of Mania: introduction (Classic text no. 57). Hist Psychiatry 2004; 15:105-124.

4. Muneer A. Treatment of the depressive phase of bipolar affective disorder: a review. J Pak Med Assoc 2013;63:763-769.

5. Cardno AG, Marshall EJ, Coid B, Macdonald AM, Ribchester TR, Davies NJ, et al. Heritability estimates for psychotic disorders: the Maudsley twin psychosis series. Arch Gen Psychiatry 1999;56:162-168.

6. Kieseppa T, Partonen T, Haukka J, Kaprio J, Lonnqvist J. High concordance of bipolar I disorder in a nationwide sample of twins. Am J Psychiatry 2004;161:1814-1821.

7. Smoller JW, Finn CT. Family, twin, and adoption studies of bipolar disorder. Am J Med Genet C Semin Med Genet 2003;123C:48-58.

8. Baum AE, Hamshere M, Green E, Cichon S, Rietschel M, Noethen MM, et al. Meta-analysis of two genome-wide association studies of bipolar disorder reveals important points of agreement. Mol Psychiatry 2008; 13:466-467.

9. Hashimoto R, Okada T, Kato T, Kosuga A, Tatsumi M, Kamijima K, et al. The breakpoint cluster region gene on chromosome $22 \mathrm{q} 11$ is associated with bipolar disorder. Biol Psychiatry 2005;57:1097-1102.

10. Cichon S, Winge I, Mattheisen M, Georgi A, Karpushova A, Freudenberg J, et al. Brain-specific tryptophan hydroxylase 2 (TPH2): a functional Pro206Ser substitution and variation in the 5'-region are associated with bipolar affective disorder. Hum Mol Genet 2008;17:87-97.

11. Liu L, Foroud T, Xuei X, Berrettini W, Byerley W, Coryell W, et al. Evidence of association between brain-derived neurotrophic factor gene and bipolar disorder. Psychiatr Genet 2008;18:267-274.

12. Ferreira MA, O’Donovan MC, Meng YA, Jones IR, Ruderfer DM, Jones $\mathrm{L}$, et al. Collaborative genome-wide association analysis supports a role for ANK3 and CACNA1C in bipolar disorder. Nat Genet 2008;40: 1056-1058.

13. Bhat S, Dao DT, Terrillion CE, Arad M, Smith RJ, Soldatov NM, et al. CACNA1C (Cav1.2) in the pathophysiology of psychiatric disease. Prog Neurobiol 2012;99:1-14.

14. Abernethy DR, Schwartz JB. Calcium-antagonist drugs. N Engl J Med 1999;341:1447-1457.

15. Bigos KL, Mattay VS, Callicott JH, Straub RE, Vakkalanka R, Kolachana $\mathrm{B}$, et al. Genetic variation in CACNA1C affects brain circuitries related to mental illness. Arch Gen Psychiatry 2010;67:939-945.

16. Chen DT, Jiang X, Akula N, Shugart YY, Wendland JR, Steele CJ, et al. 
Genome-wide association study meta-analysis of European and Asianancestry samples identifies three novel loci associated with bipolar disorder. Mol Psychiatry 2013;18:195-205.

17. Wray NR, Pergadia ML, Blackwood DH, Penninx BW, Gordon SD, Nyholt DR, et al. Genome-wide association study of major depressive disorder: new results, meta-analysis, and lessons learned. Mol Psychiatry 2012;17:36-48.

18. Psychiatric GWAS Consortium Bipolar Disorder Working Group. Large-scale genome-wide association analysis of bipolar disorder identifies a new susceptibility locus near ODZ4. Nat Genet 2011;43:977-983.

19. Roussos P, Giakoumaki SG, Georgakopoulos A, Robakis NK, Bitsios P. The CACNA1C and ANK3 risk alleles impact on affective personality traits and startle reactivity but not on cognition or gating in healthy males. Bipolar Disord 2011;13:250-259.

20. Tesli M, Skatun KC, Ousdal OT, Brown AA, Thoresen C, Agartz I, et al. CACNA1C risk variant and amygdala activity in bipolar disorder, schizophrenia and healthy controls. PLoS One 2013;8:e56970.

21. Uemura T, Green M, Warsh JJ. CACNA1C SNP rs1006737 associates with bipolar I disorder independent of the Bcl-2 SNP rs956572 variant and its associated effect on intracellular calcium homeostasis. World J Biol Psychiatry 2015:1-10.

22. Han OS, Hong JP. Structured Clinical Interview for DSM-IV Axis I Disorder-Korean Version. Seoul: Hana Medical Publishing; 2000.

23. Faul F, Erdfelder E, Buchner A, Lang AG. Statistical power analyses using $G^{*}$ Power 3.1: tests for correlation and regression analyses. Behav Res Methods 2009;41:1149-1160.

24. Sinnegger-Brauns MJ, Huber IG, Koschak A, Wild C, Obermair GJ, Einzinger $\mathrm{U}$, et al. Expression and 1,4-dihydropyridine-binding proper- ties of brain L-type calcium channel isoforms. Mol Pharmacol 2009; 75:407-414

25. Gargus JJ. Genetic calcium signaling abnormalities in the central nervous system: seizures, migraine, and autism. Ann N Y Acad Sci 2009; 1151:133-156.

26. Boczek NJ, Miller EM, Ye D, Nesterenko VV, Tester DJ, Antzelevitch C, et al. Novel Timothy syndrome mutation leading to increase in CACNA1C window current. Heart Rhythm 2015;12:211-219.

27. Shinnick-Gallagher P, McKernan MG, Xie J, Zinebi F. L-type voltagegated calcium channels are involved in the in vivo and in vitro expression of fear conditioning. Ann N Y Acad Sci 2003;985:135-149.

28. Green EK, Grozeva D, Jones I, Jones L, Kirov G, Caesar S, et al. The bipolar disorder risk allele at CACNA1C also confers risk of recurrent major depression and of schizophrenia. Mol Psychiatry 2010;15:10161022.

29. Nie F, Wang X, Zhao P, Yang H, Zhu W, Zhao Y, et al. Genetic analysis of SNPs in CACNA1C and ANK3 gene with schizophrenia: a comprehensive meta-analysis. Am J Med Genet B Neuropsychiatr Genet 2015; 168:637-648.

30. Zhang X, Zhang C, Wu Z, Wang Z, Peng D, Chen J, et al. Association of genetic variation in CACNA1C with bipolar disorder in Han Chinese. J Affect Disord 2013;150:261-265.

31. Porcelli S, Lee SJ, Han C, Patkar AA, Serretti A, Pae CU. CACNA1C gene and schizophrenia: a case-control and pharmacogenetic study. Psychiatr Genet 2015;25:163-167.

32. Jabbari K, Bernardi G. Cytosine methylation and CpG, TpG (CpA) and TpA frequencies. Gene 2004;333:143-149. 